\title{
Correction to: Multilineage differentiation of muscle-derived stem cells from GFP transgenic mice
}

\author{
Chuan Ye $\cdot$ Jiangwei Li $\cdot$ Zixu He $\cdot$ Xu Nin $\cdot$ Yi Zhang $\cdot$ Xianwen Shang \\ Riguang Liu $\cdot$ Yiqiang Duan
}

Published online: 27 November 2021

(C) Springer Nature B.V. 2021

Correction to: Biotechnol Lett (2010) 32:1745-1752 https://doi.org/10.1007/s10529-010-0344-3

In the original publication of the article, Figs. 5 and 6 were published incorrectly. The corrected figures are given below. The original article has been corrected.

The original article can be found online at https:// doi.org/10.1007/s10529-010-0344-3.

C. Ye $(\bowtie) \cdot$ J. Li · X. Nin · X. Shang $\cdot$ R. Liu · Y. Duan Department of Orthopaedics, The Affiliated Hospital of Guiyang Medical College, Guiyang 550004, China e-mail: yechuanchina@hotmail.com

C. $\mathrm{Ye} \cdot \mathrm{Z}$. He

Guizhou Research Center of Stem Cell and Tissue Engineering, Guiyang 550004, China

Z. He

Department of Pediatrics, The Affiliated Hospital of Guiyang Medical College, Guiyang 550004, China

\section{Y. Zhang}

Department of Ultrasonography, Forty-fourth Military Hospital, Guiyang 550009, China



Fig. 5 Western blot analysis of chondrogenic, neurogenic and myogenic-specific proteins. Col II, Aggrecan, GFAP and Nestin were expressed in differentiated MDSCs but not in control cultures; Myod was expressed more strongly in differentiated MDSCs than in controls 



Fig. 6 Myogenic differentiation of MDSCs. a After 3 days of culture in neurogenic medium, the cells became larger and flatter, resembling myofibroblasts. b Myogenic cells displayed a high level of GFP expression at day 3. c Immunocytochemical

Publisher's Note Springer Nature remains neutral with regard to jurisdictional claims in published maps and institutional affiliations.

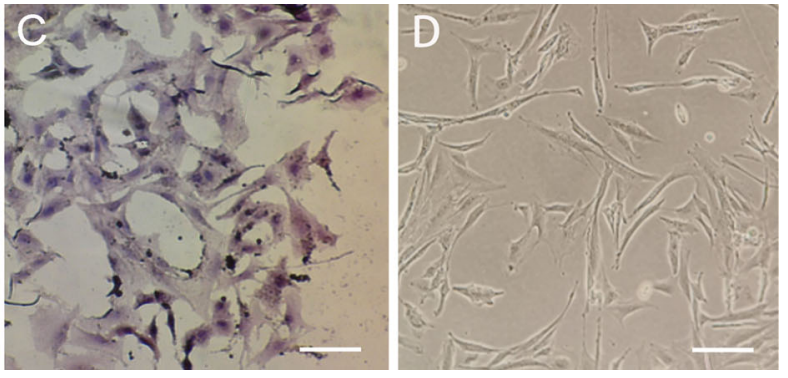

staining of $\alpha$-SMA was positive after 3 days of myogenic differentiation, but negative for the control cells (d). Bar represents $100 \mu \mathrm{m}$ 